1 Fundação Oswaldo Cruz (Fiocruz), Escola Nacional de Saúde Pública Sergio Arouca (Ensp) - Rio de Janeiro (RJ), Brasil. fernando.bessa@ensp. fiocruz.br

2 Fundação Oswaldo Cruz (Fiocruz), Escola Naciona de Saúde Pública Sergio Arouca (Ensp) - Rio de Janeiro (RJ), Brasil. ribeiro@ensp.fiocruz.br

3 Fundação Oswaldo Cruz (Fiocruz), Escola Nacional de Saúde Pública Sergio Arouca (Ensp) - Rio de Janeiro (RJ), Brasil. rasga@ensp.fiocruz.br

\section{A saúde do adolescente privado de liberdade: um olhar sobre políticas, legislações, normatizações e seus efeitos na atuação institucional}

The health of the adolescent deprived of freedom: a look at policies, laws, norms and its effects on institutional performance

Fernando Manuel Bessa Fernandes ${ }^{\mathbf{1}}$, José Mendes Ribeiro ${ }^{\mathbf{2}}$, Marcelo Rasga Moreira ${ }^{\mathbf{3}}$

RESUMO O objetivo do artigo é subsidiar o debate sobre os efeitos que o conjunto de peças jurídico-administrativas e político-legislativas tem na atuação institucional e na práxis dos gestores e profissionais dos sistemas socioeducativo e de saúde. Levantaram-se e analisaram-se as leis, portarias, resoluções, normas, textos acadêmicos e institucionais que embasam e constituem a política de saúde voltada aos adolescentes infratores no Brasil. Há assimetria entre as legislações e normatizações e a realidade das unidades socioeducativas, o que torna urgente superar as barreiras de preconceito e estigmatização via investimento em recursos humanos e parcerias governamentais interinstitucionais.

PALAVRAS-CHAVE Saúde pública; Políticas públicas de saúde; Saúde do adolescente; Adolescente institucionalizado; Saúde do adolescente institucionalizado.

ABSTRACT The paper aims to support the debate on the effects that the set of legal, administrative and political pieces of legislation have on institutional performance and practice of managers and professionals from the socio-educational and health systems. Laws, ordinances, resolutions, regulations, academic and institutional texts were raised and analyzed that support and provide the health policy dedicated to offenders adolescents in Brazil. There is asymmetry between the laws and norms and the reality of Socio-Educational Units, which makes it urgent to overcome the barriers of prejudice and stigmatization through investment in human resources and intergovernmental partnerships.

KEYWORDS Public health; Public health policies; Adolescent health; Adolescent, institutionalized; Health of institutionalized adolescents. 


\section{Introdução}

A atenção integral à saúde de adolescentes no Brasil é um tema que envolve aspectos polêmicos e representa um desafio bastante considerável para estudiosos e, principalmente, para os gestores públicos. A simples observação do cotidiano e a apreciação da literatura acadêmica revelam que questões político-ideológicas, valores morais e preconceitos comportamentais sobre a adolescência são notáveis. Povoam de forma intensa e arraigada os corações e mentes de gestores e profissionais das áreas da saúde, da educação e do direito, com potencial de consistirem em entraves e, até mesmo, em alguns casos, na inviabilização de iniciativas governamentais voltadas para a melhoria das condições de vida, do bem-estar e da saúde daquele grupo populacional.

A situação se agudiza exponencialmente no que diz respeito ao asseguramento do direito à saúde de adolescentes que cometeram algum ato infracional grave o suficiente para ingressar no sistema socioeducativo e demandar o cumprimento de medida socioeducativa de internação e/ou internação provisória, conforme a legislação específica para o infrator adolescente: o Estatuto da Criança e do Adolescente (ECA) (BRASIL, 1990).

Segundo essa legislação, o adolescente em conflito com a lei é todo o jovem, entre 12 e 18 anos, que cometeu algum ato infracional. Já o chamado sistema socioeducativo é a esfera governamental que aplica as medidas de socioeducação ou socioeducativas, a fim de responsabilizar o jovem que infracionou alguma lei. As medidas socioeducativas se dividem em medidas privativas de liberdade e não privativas, e, nomeadamente, têm como maior preocupação a responsabilização do ato e a reflexão. As medidas privativas de liberdade são a internação e a semiliberdade, ao passo que as não privativas de liberdade são a advertência, a obrigação de reparar o dano, a prestação de serviço à comunidade e a liberdade assistida.

O tempo de cumprimento dessas medidas socioeducativas é determinado por um juiz da Vara da Infância e da Juventude. Na internação, que é a medida mais severa, o prazo máximo para cumprir a medida é de três anos. Depois disso, o adolescente sairá compulsoriamente, não tendo nenhum resquício em seus registros sociais. Caso infracione mais vezes, o prazo de cumprimento da medida poderá ser revisto e se estender, no máximo, até que ele atinja 21 anos de idade.

Durante o tempo de cumprimento de medida de privação de liberdade, o adolescente está sob tutela e responsabilidade do Estado. E o Estado, aqui, por força da conformação burocrático-administrativa do sistema socioeducativo, institui-se nos estados-membros da federação. $O$ direito de ir e vir dos adolescentes nessa situação foi suspenso, mas seu direito à saúde, não. É, pois, dever do poder público garantir esse direito, aliado ao dever de oferecer serviços de atendimento à saúde para todo e qualquer cidadão, seja em qual situação jurídico-legal ele estiver.

Estudos e levantamentos têm verificado a ocorrência de uma assimetria entre o que é considerado desejável, cristalizado nas legislações e normatizações concernentes, e o que é detectado na realidade cotidiana das unidades socioeducativas de internação e internação provisória no que tange à violação de direitos (OLIVEIRA; ASSIS, 1999; RAPOSO, 2013; VILLAS BOAS; CUNHA; CARVALHO, 2010; UNICEF, 2012).

Quando se pensa em termos de atendimento à saúde, percebe-se que os adolescentes privados de liberdade, por estarem cumprindo medida de internação e internação provisória, consistem em clientela do Sistema Único de Saúde (SUS), assim como qualquer outra pessoa, criança, adolescente ou adulta, sem distinções de qualquer tipo. Isso, a priori, seria um direito constitucional pétreo que não admitiria discussão ou flexibilização. Porém, a realidade nem sempre se coaduna com a legislação e a normatização. $\mathrm{E}$, o que é pior, nem com os princípios mais elementares de civilidade e humanidade. É nesse panorama de complexidade relacional 
que as instâncias responsáveis pela saúde dos adolescentes, nos três níveis governamentais, devem trabalhar.

Impõe-se, portanto, um desafio aos gestores públicos responsáveis pela formulação, implementação, execução e avaliação de políticas de saúde para esse contingente específico, tanto em níveis subnacionais locais quanto na esfera federal: desenvolver capacidade institucional de atuação competente e hábil para lidar com vicissitudes, dificuldades, arranjos, resistências, institucionais ou individuais, no âmbito das relações entre a saúde e o sistema socioeducativo, levando em conta e observando o conjunto de documentos que constituem os aparatos jurídico-administrativo e político-legislativo concernentes.

Na esfera federal, a instância responsável pela formulação e implementação de ações, estratégias e políticas de saúde para a população adolescente (e jovem, compreendido como o indivíduo com idade de até 24 anos), atualmente, é a Coordenação-Geral de Atenção à Saúde do Adolescente e do Jovem, do Departamento de Ações Programáticas e Estratégicas da Secretaria de Atenção à Saúde do Ministério da Saúde - doravante denominada CGSAJ/Dapes/SAS/MS.

Especialmente para a população adolescente privada de liberdade, a CGSAJ/Dapes/ SAS/MS formulou e tem implementado, junto às instâncias parceiras das três esferas, a Política Nacional de Atenção Integral à Saúde de Adolescentes e Jovens em Conflito com a Lei em Regime de Internação e Internação Provisória - daqui por diante, neste texto, denominada PNAISARI (BRASIL, 2012A).

Isto posto, este artigo tem por objetivo oferecer subsídios para o debate sobre os efeitos que o conjunto de peças jurídico-administrativas e político-legislativas relativas à saúde do adolescente cumprindo medida socioeducativa privado de liberdade tem na atuação institucional das instâncias responsáveis pela saúde dessa população e na práxis dos gestores e profissionais do sistema socioeducativo e do SUS.

\section{Métodos}

$\mathrm{O}$ presente artigo se baseia na experiência do autor, que integra uma equipe de pesquisa que tem desenvolvido reflexões e estudos avaliativos de caráter crítico-propositivo para a CGSAJ/Dapes/SAS/MS.

Levantaram-se as leis, portarias, resoluções e normas, aqui chamadas de peças jurídico-administrativas e político-legislativas, que embasam e constituem as políticas da CGSAJ/Dapes/SAS/MS mais diretamente relacionadas à consolidação da PNAISARI. Igualmente, levantaram-se textos acadêmicos e institucionais correlacionados e considerados pertinentes. A seguir, procedeu-se a uma análise reflexiva a partir do material documental levantado.

\section{Resultados e discussão}

A PNAISARI foi instituída pela Portaria Interministerial $\mathrm{n}^{\circ} 1.426$, de 14/07/04, (BRASIL, 2004A), de autoria conjunta do Ministério da Saúde, da Secretaria Especial de Direitos Humanos da Presidência da República (SEDH/PR) e da Secretaria Especial de Políticas para as Mulheres da Presidência da República (SEPM/PR). Essa política, portanto, foi inspirada e concebida a partir da necessidade de aprofundar a discussão, a articulação e a responsabilização entre os setores e atores que já têm desenvolvido e que dispõem de recursos e condições de desenvolver ações de saúde dirigidas aos adolescentes em conflito com a lei e privados de liberdade.

Essa política está inserida no grande portfólio de atuação institucional da CGSAJ/ Dapes/SAS/MS, consubstanciado nas Diretrizes Nacionais para a Atenção à Saúde de Adolescentes e Jovens na Promoção, Proteção e Recuperação da Saúde, que também são conhecidas como Política Nacional de Atenção Integral à Saúde de Adolescentes e Jovens (PNAISAJ) (BRASIL, 2014; RAPOSO, 2009; VILLAS BOAS ET AL., 2010). 
Do conjunto de legislações e normatizações da saúde de adolescentes no Brasil, destaca-se a publicação 'Marco legal: saúde, um direito de adolescentes', elaborada pela CGSAJ/Dapes/SAS/MS, em 2005, que relaciona instrumentos legais de proteção aos direitos dessa população, notadamente aqueles de garantia do pleno exercício de seu direito fundamental à saúde, em âmbito nacional e internacional. Esse é um importante documento para subsidiar os profissionais e gestores que atuam na área da saúde de adolescentes, fornecendo elementos para a tomada de decisões, para a elaboração de políticas públicas, para o atendimento nos serviços de saúde, com o intuito de divulgar e discutir os direitos dos adolescentes (BRASIL, 2005).

Já a PNAISARI foi inicialmente parametrizada em seus critérios e fluxos pela Portaria SAS n ${ }^{\circ} 340$, também de 14/07/04 (BRASIL, 2004B), posteriormente substituída pela Portaria SAS n $n^{0} 647$, de 11/11/08 (BRASIL, 2008), e apresentava como principal característica a promoção da integração do SUS com o sistema socioeducativo, na medida em que busca trazer a garantia do direito à saúde dos adolescentes para as Unidades Socioeducativas de Internação e Internação Provisória (USE).

Pretendia-se que isso se desdobrasse num modelo de atenção integral à saúde moderno, humano, dotado de organicidade e marcado por: a) Combate à violência em suas variadas formas ao reduzir problemas e agravos pela prevenção, promoção e assistência à saúde; b) Cumprimento do princípio da incompletude institucional, afirmando os preceitos da Reforma Psiquiátrica pela supressão das famigeradas 'instituições totais'; c) Interdisciplinaridade dos atores envolvidos - entendidos como pessoas, secretarias, departamentos, coordenações e áreas técnicas federais, estaduais e municipais, assim como outras entidades, governamentais ou não; e d) Defesa do binômio educação e saúde.

Para a gestão federal concentrada na CGSAJ/Dapes/SAS/MS, a PNAISARI significa a tarefa diuturna de reforço do modelo de atenção, tarefa essa que não se dissocia da consolidação da garantia do direito constitucional à saúde aos adolescentes privados de liberdade, posto que estão entre a parcela de cidadãos mais fragilizados e em situação de vulnerabilidade e cujas demandas têm sido menos atendidas ou atendidas com maior precariedade, dentre o universo de adolescentes brasileiros.

Isso ocorre tanto por conta da estigmatização que sofrem de parte de profissionais da rede de atendimento do SUS, por estarem em situação de conflito com a lei e privados de liberdade, quanto por conta das dificuldades e iniquidades a que estão passíveis de serem submetidos por estarem inseridos no sistema socioeducativo, no próprio interior deste, nas unidades socioeducativas.

Não pode ser ignorado o hiato existente entre a legislação, a normatização e as políticas e a realidade nas unidades socioeducativas, conforme se tem observado no País (FERNANDES ET AL., 2008; HORTA; SENA, 2010; OLIVEIRA; ASSIS, 1999; UNICEF, 2012; SILVA; GUERESE, 2003).

Destarte, surge uma indagação: como pode ser efetiva uma política de saúde de abrangência nacional voltada para essa população específica, levando-se em conta os efeitos dos documentos oficiais de caráter jurídico-administrativo e político-legislativo na atuação institucional da instância federal responsável, a CGSAJ/Dapes/SAS/MS e, também, dos gestores e profissionais do SUS e do sistema socioeducativo?

A seguir, para auxílio na busca de respostas para esse e outros questionamentos, apresenta-se um quadro com o conjunto de peças jurídico-administrativas e político-legislativas (Leis, Portarias, Resoluções e Normas) que embasam a política de saúde de adolescentes e jovens no País, e que estão mais diretamente relacionadas à consolidação da PNAISARI. O quadro 1 está divido em colunas indicadoras de peça e seus respectivos ano e disposição, a fim de identificar e qualificar cada proposição em correlação com a política: 
Quadro 1. Peças jurídico-administrativas e político-legislativas diretamente relacionadas à consolidação da Política de Saúde dos Adolescentes Privados de Liberdade no Brasil

\begin{tabular}{|c|c|c|}
\hline PEÇA & ANO & DISPOSIC̣ÃO \\
\hline $\begin{array}{l}\text { Constituição da República } \\
\text { Federativa do Brasil }\end{array}$ & 05/10/1988 & $\begin{array}{l}\text { Carta Magna, Lei Máxima do País. Afirmação das noções de saúde como direito, de crianças e } \\
\text { adolescentes enquanto sujeitos de direitos e de proteção social }\end{array}$ \\
\hline Lei no 8.069 & 13/07/1990 & Dispõe sobre o Estatuto da Criança e do Adolescente (ECA) e dá outras providências \\
\hline Lei no 8.742 & 07/12/1993 & Dispõe sobre a organização da assistência social e dá outras providências \\
\hline Lei no 12.594 & 18/01/2012 & $\begin{array}{l}\text { Institui o Sistema Nacional de Atendimento Socioeducativo (Sinase), regulamenta a execução das } \\
\text { medidas socioeducativas e dá outras providências }\end{array}$ \\
\hline Portaria MS/SAS no I.101 & $12 / 06 / 2001$ & Estabelece os parâmetros de cobertura assistencial no âmbito do SUS \\
\hline $\begin{array}{l}\text { Portaria Interministerial MS/ } \\
\text { SDH/SPM no } 1426\end{array}$ & 14/07/2004 & $\begin{array}{l}\text { Aprova as diretrizes para a implementação da atenção à saúde dos adolescentes em conflito com a lei, } \\
\text { em regime de internação e internação provisória, e dá outras providências }\end{array}$ \\
\hline Portaria MS/SAS no 340 & 14/07/2004 & $\begin{array}{l}\text { Aprova as Normas para a Implantação e Implementação da Atenção à Saúde dos Adolescentes } \\
\text { em Conflito com a Lei, em Regime de Internação e Internação Provisória, em unidades masculinas } \\
\text { e femininas, a Padronização Física do Estabelecimento de Saúde nas Unidades de Internação e } \\
\text { Internação Provisória, o Plano Operativo Estadual de Atenção Integral à Saúde dos Adolescentes em } \\
\text { conflito com a lei, em Regime de Internação e Internação Provisória e o Termo de Adesão }\end{array}$ \\
\hline Portaria MS/SAS no 204 & 29/01/2007 & $\begin{array}{l}\text { Regulamenta o financiamento e a transferência dos recursos federais para as ações e os serviços de } \\
\text { saúde, na forma de blocos de financiamento, com o respectivo monitoramento e controle }\end{array}$ \\
\hline Portaria MS/GM no 2.817 & 08/11/2006 & $\begin{array}{l}\text { Habilita o Distrito Federal a receber o Incentivo para Atenção Integral à Saúde de Adolescentes em } \\
\text { Conflito com a Lei }\end{array}$ \\
\hline Portaria MS/SAS no 647 & $11 / 11 / 2008$ & $\begin{array}{l}\text { Aprova as Normas para a Implantação e Implementação da Política de Atenção Integral à Saúde dos } \\
\text { Adolescentes em Conflito com a Lei, em Regime de Internação e Internação Provisória (PNAISARI), } \\
\text { em unidades masculinas e femininas, os parâmetros para construção, ampliação ou reforma de } \\
\text { estabelecimento de saúde nas Unidades de Internação e Internação Provisória e o Plano Operativo } \\
\text { Estadual de Atenção Integral à Saúde dos Adolescentes em conflito com a lei, em Regime de } \\
\text { Internação e Internação Provisória }\end{array}$ \\
\hline Portaria MS/GM no 1.992 & 19/08/2011 & $\begin{array}{l}\text { Altera o Anexo da Portaria no } 2.817 / G M / M S \text {, de } 8 \text { de novembro de 2006, ao incluir Unidades } \\
\text { Socioeducativas aptas ao recebimento de Incentivos Financeiros para Atenção Integral à Saúde de } \\
\text { Adolescentes Privados de Liberdade }\end{array}$ \\
\hline Portaria MS/GM n 1.082 & 23/05/2014 & $\begin{array}{l}\text { Redefine as diretrizes da Política Nacional de Atenção Integral à Saúde de Adolescentes em Conflito com a Lei } \\
\text { (PNAISARI), incluindo-se o cumprimento de medida socioeducativa em meio aberto e fechado; e estabelece } \\
\text { novos critérios e fluxos para adesão e operacionalização da atenção integral à saúde de adolescentes }\end{array}$ \\
\hline Portaria GM/MS no 1.083 & 23/05/2014 & $\begin{array}{l}\text { Institui o incentivo financeiro de custeio para o ente federativo responsável pela gestão das ações de } \\
\text { atenção integral a saúde dos adolescentes em situação de privação de liberdade, de que trata o art. } 24 \\
\text { e parágrafo único da Portaria no } 1.082 / G M / M S \text {, de } 23 \text { de maio de } 2014\end{array}$ \\
\hline Portaria MS/SAS no 973 & 29/09/2014 & $\begin{array}{l}\text { Estabelece normas para o cadastramento no Sistema de Cadastro Nacional de Estabelecimentos de } \\
\text { Saúde (SCNES) das equipes e serviços que farão parte da Política Nacional de Atenção Integral à } \\
\text { Saúde de Adolescentes em Conflito com a Lei (PNAISARI) }\end{array}$ \\
\hline Resolução Conanda no 46 & 29/10/1996 & Regulamenta a execução da medida socioeducativa de internação prevista no ECA \\
\hline Resolução Conanda no 119 & $11 / 112006$ & Dispõe sobre o Sinase e dá outras providências \\
\hline Resolução Conanda no 160 & $18 / 11 / 2013$ & Institui o Plano Nacional de Atendimento Socioeducativo \\
\hline $\begin{array}{l}\text { Marco Legal: Saúde, um } \\
\text { direito de Adolescentes }\end{array}$ & 2005 & $\begin{array}{l}\text { Apresenta instrumentos legais de proteção aos direitos dessa população, notadamente aqueles de } \\
\text { garantia do pleno exercício de seu direito fundamental à saúde, em âmbito nacional e internacional. }\end{array}$ \\
\hline $\begin{array}{l}\text { Caminhos para uma Política de } \\
\text { Saúde Mental Infanto-Juvenil }\end{array}$ & 2005 & $\begin{array}{l}\text { Apresenta considerações técnicas fundamentais para a discussão e implementação da política de } \\
\text { saúde mental voltada para a população infanto-juvenil no âmbito do SUS }\end{array}$ \\
\hline $\begin{array}{l}\text { Linha de cuidado para a } \\
\text { Atenção Integral à Saúde de } \\
\text { Crianças, Adolescentes e } \\
\text { suas Famílias em Situação de } \\
\text { Violências }\end{array}$ & 2010 & $\begin{array}{l}\text { Fornece orientação para gestores e profissionais de saúde para contribuir na identificação de sinais e } \\
\text { sintomas de violências e estabelece uma linha de cuidado para a atenção integral à saúde de criança, } \\
\text { adolescente e suas famílias em situação de violências, articulada com a rede de cuidado e de proteção } \\
\text { social existente nos territórios }\end{array}$ \\
\hline $\begin{array}{l}\text { Diretrizes Nacionais para } \\
\text { a Atenção à Saúde de } \\
\text { Adolescentes e Jovens } \\
\text { na Promoção, Proteção e } \\
\text { Recuperação da Saúde }\end{array}$ & 2010 & $\begin{array}{l}\text { Apresenta orientação baseada na Política Nacional de Atenção Integral à Saúde de Adolescentes e } \\
\text { Jovens (PNAISAJ) para ações integradas à outras políticas sanitárias, ações e programas já existentes } \\
\text { no SUS }\end{array}$ \\
\hline
\end{tabular}

Fonte: Elaboração própria. 
Para além da própria dificuldade em elaborar e converter uma proposição governamental em política (LOPEZ; MOREIRA, 2013), talvez um dos grandes desafios enfrentados na implementação e execução da PNAISARI esteja na discrepância e no conflito de lógicas entre os documentos e as práticas cotidianas de atendimento do adolescente em conflito com a lei e privado de liberdade.

A lógica do SUS se choca com as características de instituição total que as unidades socioeducativas de internação e internação provisória ainda apresentam, pelos discursos e práticas usuais dos profissionais e gestores nelas observadas. Por seu turno, a lógica das legislações e normatizações encontra consideráveis dificuldades de ressonância e concretização no cotidiano das unidades socioeducativas.

Tais fatores obstaculizam a plena execução de ações sistematizadas, articuladas e integradas visando ao atendimento das necessidades dos adolescentes, em suas diversificadas dimensões de realidade, em cumprimento dos princípios, valores e diretrizes estabelecidas na Constituição Federal de 1988 e nos dispositivos legais, assim como nas normatizações.

Considerando-se saúde como bem-estar em todos os sentidos e possibilidades de desenvolvimento da pessoa, com direitos humanos e sociais consagrados na legislação, a estruturação de um sistema de garantia de direitos da criança e do adolescente infere-se a partir do ECA e passa pela ideia de articulação e integração em rede das instâncias públicas governamentais e da sociedade civil, na aplicação de instrumentos normativos e no funcionamento dos mecanismos de promoção, defesa e controle para a efetivação dos direitos da criança e do adolescente, nos níveis federal, estadual, distrital e municipal (BRASIL, 2012C).

Sob a égide desse sistema de garantia de direitos, instituiu-se, em 18 de janeiro de 2012, o Sistema Nacional de Acompanhamento Socioeducativo (Sinase), pela Lei Federal
12.594/2012 (BRASIL, 2012B), também regido pelos artigos referentes à socioeducação do ECA, pela Resolução 119/2006, do Conselho Nacional dos Direitos da Criança e do Adolescente (Conanda) (BRASIL, 2006), e pela Resolução 160/2013, também do Conanda, que institui o Plano Nacional de Atendimento Socioeducativo (BRASIL, 2013).

A coordenação do Sinase, inserida na estrutura da Secretaria de Direitos Humanos da Presidência da República (SDH/PR), é o locus do governo federal responsável pela aplicação das medidas socioeducativas, em consonância com os diferentes ministérios e outras instâncias nacionais, e também com as instâncias subnacionais correlatas, ao estabelecer diretrizes nacionais de atuação e parâmetros no âmbito da arquitetura, segurança, gestão e socioeducação para as unidades socioeducativas.

Ao evidenciarem-se as dificuldades de entendimento das especificidades do relacionamento entre as diversas áreas envolvidas, em particular, a saúde, foi, tem sido e será especialmente fundamental para a PNAISARI que a CGSAJ/Dapes/SAS/MS mantenha um bom relacionamento com a coordenação do Sinase, a fim de que se fortaleça a viabilidade das articulações e ações preconizadas, tanto no sentido dos direitos humanos quanto no dos direitos sociais, e, nestes, o direito à saúde. Em outras palavras, põe-se para a CGSAJ/Dapes/SAS/MS a demanda de promoção constante do entrelaçamento e da potencialização mútua de interesses convergentes de atores e instituições envolvidos.

Porém, tendem à escassez articulações mais estreitas e efetivas com outros órgãos estratégicos, tais como a Secretaria Nacional de Juventude da Presidência da República (SNJ/PR), as Varas de Infância e Juventude e o Ministério Público, o que incide na própria situação dos adolescentes em privação de liberdade, seja em função da ausência de propostas de modificação e incremento da cultura organizacional e das ações de atendimento nas unidades socioeducativas, seja 
por conta de um desencontrado monitoramento e da aplicação de sanções aos gestores que protagonizam ou permitem violações dos direitos dos adolescentes.

No que tange às sanções direcionadas aos adolescentes, a quantidade de aplicações de medidas de internação no Brasil tem crescido em decorrência de um aumento detectado na incidência de atos infracionais e também da tendência de setores mais conservadores do Judiciário de pronunciarem medidas punitivas mais severas (BRASIL, 2012B).

Tal fato alerta para a importância e para a urgência de políticas públicas eficazes e efetivas, assim como para a relevância de se imaginar e construir estratégias de inovação e estabelecimento de iniciativas que atuem de forma preventiva na realidade dos adolescentes. Esse alerta deve considerar, ainda, que a relação entre a população de adolescentes em geral e a população de adolescentes infratores tem acompanhado o crescimento da população brasileira como um todo (BRASIL, 2010B; BRASIL, 2012B; UNICEF, 2012).

Contudo, independentemente da idade e da quantidade de habitantes e de infratores, o Estado brasileiro tem o dever constitucional de prover e garantir todas as condições materiais e não materiais de existência a eles, enquanto estiverem sob sua responsabilidade, e de garantir seus direitos. A despeito de um de seus direitos estar suspenso - o direito de ir e vir -, teoricamente, os outros não deveriam estar sendo negados ou obstaculizados, posto que se trata de cidadãos que habitam o território nacional e têm direito à saúde, ainda que estejam privados de liberdade.

Todavia, sabe-se que isso não é a práxis hegemônica ou predominante nas unidades socioeducativas, infelizmente. A história do sistema socioeducativo perpetua legados de sua condição punitiva calcada em valores morais e autoritários, e, de modo a agir para transformar essa realidade, o Sinase se propõe a modernizar e oxigenar o modelo estadualizado tradicional de justiça para aqueles indivíduos que não atingiram a maioridade penal. Maioridade penal que, não surpreendentemente, tem estado sob a constante mira de setores conservadores da sociedade e de seus representantes no Poder Legislativo.

Por conseguinte, o caminho a ser percorrido ainda é longo, e obstáculos são visíveis e consideráveis, ainda mais quando se observam as condições nas quais o direito constitucional à saúde dessa população tem sido tratado: ordem, disciplina, punição, penitência, purgação. Esses signos povoam a cultura organizacional no cotidiano das unidades socioeducativas, deformando o sentido da própria socioeducação ao alimentarem-se das diretivas expostas nas legislações e normatizações para retroalimentarem posicionamentos conservadores e moralistas.

O cerne do conflito de lógicas entre as legislações e normatizações e os discursos e práticas nas unidades socioeducativas, no que diz respeito à saúde dos adolescentes privados de liberdade, parece estar, pois, no princípio que rege as ações cotidianas dos envolvidos.

Gestores e profissionais do sistema socioeducativo, quando apresentam comportamento descolado do espírito que emana das legislações e normatizações e que está calcado em preconceitos e valores morais, reforçam uma estrutura punitivista, atentatória à dignidade da pessoa humana. E mesmo os profissionais do setor saúde (os quais, a princípio, por força da disseminação dos princípios humanistas do SUS, apresentariam comportamento mais afeito à defesa dos direitos sociais) também estão sujeitos a apresentar comportamento conflituoso com o que seria de se esperar, no sentido da formação cidadã e da socioeducação.

$\mathrm{O}$ aprofundamento dessa questão específica da formação e dos constantes aperfeiçoamentos, atualização e capacitação profissional significaria um desvio do foco do presente texto, mas aqui fica apontada a sua inegável importância. O investimento na formação de recursos humanos e o refinamento 
constante de práticas cotidianas são ações que não podem ser relegadas a segundo plano, sob pena de se configurar retrocesso nas formas de lidar com a situação do adolescente que cumpre medida socioeducativa.

Por certo, o adolescente em conflito com a lei, privado de liberdade e do seu direito à saúde, é o ponto focal para o qual convergem questões contraditórias, de natureza bastante delicada e dificultosa. A figura 1 congrega o conjunto de reflexões expostas neste artigo na forma de mapa conceitual, construindo um panorama da relação entre a saúde e a socioeducação no Brasil:

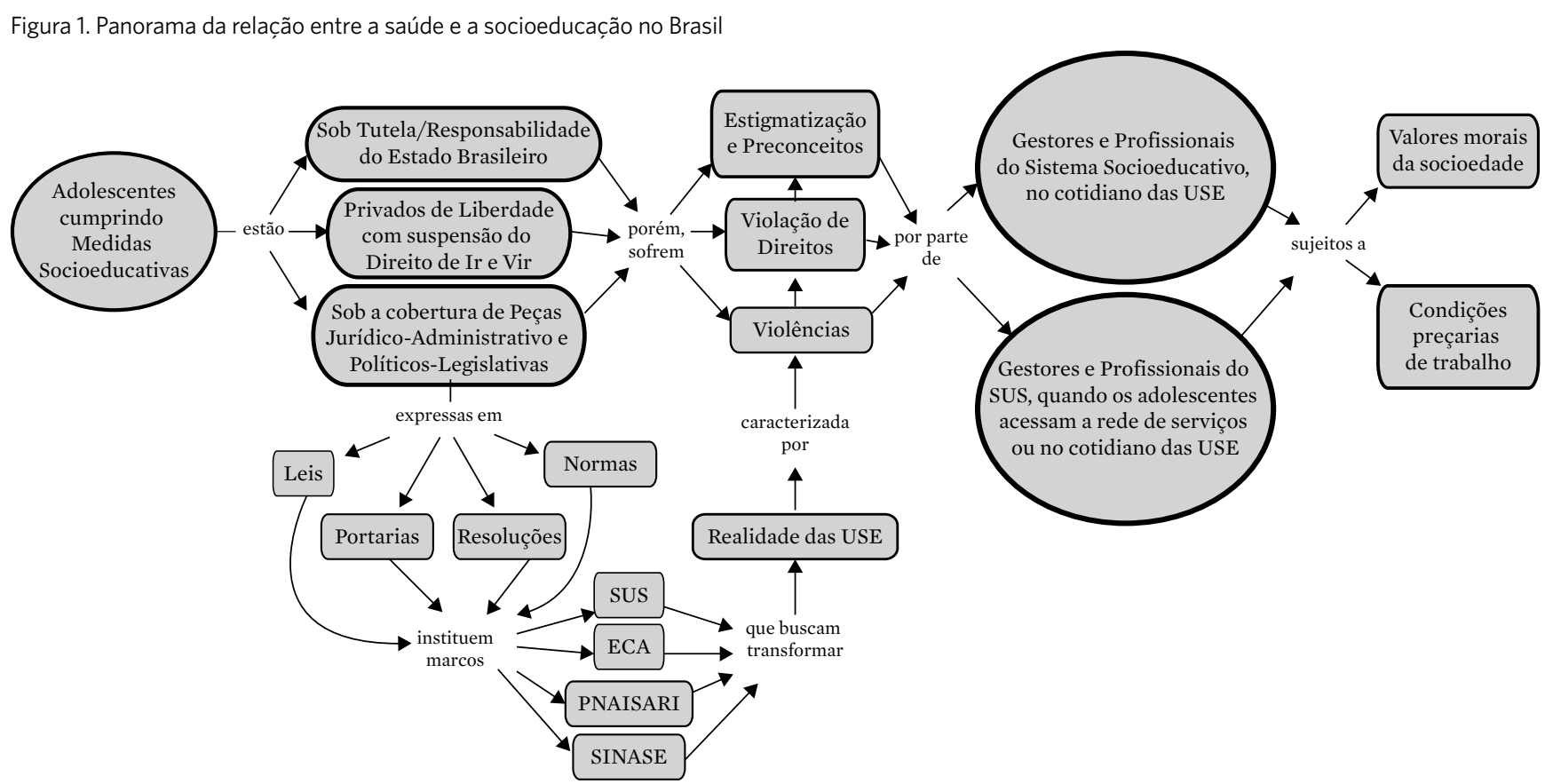

Fonte: Elaboração própria.

Na esteira de todo o conjunto de peças jurídico-administrativas e político-legislativas embasadoras da política de saúde de adolescentes e jovens no País, e que estão mais diretamente relacionadas à consolidação da PNAISARI, a proposição de um sistema como o Sinase, compreendendo uma coordenação federal da socioeducação, surge como uma esperançosa medida para influenciar positivamente $o$ conceito de socioeducação e o ethos vigentes entre os gestores e profissionais das unidades socioeducativas de internação e internação provisória e do SUS. Mas quais seriam as reais possibilidades de fundamentação e sucesso de tal proposta? Essa é uma questão que não se pretende responder cabalmente aqui.
O que se pretende é indicar e ressaltar a importância do debate e trazer à luz a percepção de que se coloca um grande desafio para a coordenação do Sinase e, principalmente, para a CGSAJ/Dapes/SAS/MS: a superação das barreiras de forte preconceito e estigmatização enfrentadas pela população de indivíduos cumprindo medidas socioeducativas de internação e internação provisória. Se adolescentes em geral, costumeiramente, já sofrem uma condição de parcial invisibilidade do olhar dos profissionais de saúde nos serviços públicos, adolescentes em conflito com a lei e privados de liberdade são ainda mais invisíveis. Ou, por outro lado, a eles é conferida uma visibilidade pontual, 
extremamente negativa - regida pelo preconceito e pela discriminação, pelo fato de serem infratores -, que só emerge quando da sua eventual necessidade de um atendimento em saúde, nos serviços da rede SUS.

No processo de implementação da PNAISARI, isso fica muito evidente, no sentido da dificuldade dos gestores e profissionais de saúde subnacionais de compreenderem que é deles a responsabilidade do atendimento, significando garantia de direitos, e também dos gestores e profissionais do próprio sistema socioeducativo, no que tange aos aspectos operacionais e culturais componentes do modus operandi do trabalho nas unidades socioeducativas de internação e internação provisória.

\section{Considerações finais}

Se a responsabilidade de gerir as políticas públicas concernentes à população adolescente em articulação com as instâncias congêneres situadas nos entes federativos subnacionais (coordenações estaduais e municipais do sistema socioeducativo) não pode prescindir da interlocução e da interação com as instâncias responsáveis pela saúde nas três esferas da administração pública (a CGSAJ/Dapes/ SAS/MS e as secretarias e coordenações estaduais e municipais), ambas não podem abrir mão de outras parcerias e da atuação em campos que extrapolam os da gestão da saúde e da socioeducação.

Da interlocução e da interação entre os atores envolvidos, principalmente com instâncias do Poder Judiciário consubstanciadas nas Varas de Infância e Juventude, viabilizam-se possibilidades de transformações de valores, consciências, culturas e práticas. A desconstrução de uma lógica carcerária e medieval de tortura, punição e negação de direitos deve vir casada com um investimento maciço na formação de recursos humanos voltados, especialmente, para o trabalho com a socioeducação. $\mathrm{O}$ investimento deve ocorrer, também, na melhoria das condições de trabalho nas unidades socioeducativas, dado que influenciam sobremaneira a cultura organizacional.

Tão importante quanto isso é a urgência de construção e consolidação de condições de vida dignas para a população adolescente, o que significa dizer que a tarefa demanda trabalho em rede, conectando aspirações e promovendo conscientização e aprendizado constantes. Se existe a consciência de que esse esforço não é nada pequeno, também existe a perspectiva de que as linhas que se vislumbram no horizonte podem se concretizar.

Do mesmo modo, a partir da interação e integração inteligentes de todos os envolvidos, podem ser viabilizadas alternativas republicanas e democráticas de incremento e mesmo de superação incremental de legislações, normatizações e políticas vigentes, na defesa, na proteção e na salvaguarda dos direitos humanos, civis e sociais da população adolescente em privação de liberdade, com destaque para o direito à saúde, em conformidade com os mais altos princípios civilizatórios. 


\section{Referências}

BRASIL. Marco legal: saúde, um direito de adolescentes. Brasília, DF: Ministério da Saúde, 2005. Disponível em: $<$ http://bvsms.saude.gov.br/bvs/ publicacoes/07_0400_M.pdf>. Acesso em: 13 maio 2015. (Série A, Normas e Manuais Técnicos).

Ministério da Saúde. Secretaria de Atenção à Saúde. Portaria No 340 , de 14 de julho de 2004. Aprova, na forma dos anexos I, II, III e IV desta portaria, as normas para a implantação e implementação da atenção à saúde dos adolescentes em conflito com a lei, em regime de internação e internação provisória, em unidades masculinas e femininas, a padronização física do estabelecimento de saúde nas unidades de internação e internação provisória, o plano operativo estadual de atenção integral à saúde dos adolescentes em conflito com a lei, em regime de internação e internação provisória e o termo de adesão. Diário Oficial [da] União. Brasília, DF, 15 jul. 2004b. Disponível em: <http://bvsms.saude.gov.br/bvs/saudelegis/sas/2004/ prt0340_14_07_2004.html>. Acesso em: 13 maio 2015.

Ministério da Saúde. Secretaria de Atenção à Saúde. Secretaria de Direitos Humanos. Secretaria de Política para Mulheres. Portaria Interministerial $n^{\circ}$ 1.426, de 14 de julho de 2004. Aprova as diretrizes para a implantação e implementação da atenção à saúde dos adolescentes em conflito com a lei, em regime de internação e internação provisória, e dá outras providências. Diário Oficial [da] União. Brasília, DF, 15 out. 2004a. Disponível em: <http://bvsms.saude.gov.br/bvs/saudelegis/gm/2004/pri1426_14_07_2004.html>. Acesso em: 13 maio 2015.

Política Nacional de Atenção Integral à Saúde de Adolescentes em Conflito com a Lei: normas e reflexões. Brasília, DF: Ministério da Saúde, 2002. Disponível em: <http://www.saude.sp.gov.br/resources/ses/perfil/ profissional-da-saude/grupo-tecnico-de-acoes-estrategicas-gtae/saude-das-populacoes-privadas-de-liberdade/saude-dos-adolescentes-em-conflito-com-a-lei/ legislacao/pnaisari_17_01_2012_versao_preliminar. pdf>. Acesso em: 13 maio 2015. (Série B, Textos Básicos de Saúde).
Portaria ${ }^{\circ}$ 647, de 11 de novembro de 2008.

Aprova, na forma dos anexos I, II, III e IV desta portaria, as normas para a implantação e implementação da política de atenção integral à saúde dos adolescentes em conflito com a lei, em regime de internação e internação provisória - PNAISARI, em unidades masculinas e femininas, os parâmetros para construção, ampliação ou reforma de estabelecimento de saúde nas unidades de internação e internação provisória e o plano operativo estadual de atenção integral à saúde dos adolescentes em conflito com a lei, em regime de internação e internação provisória. Diário Oficial [da] União. Brasília, DF, 12 nov. 2008. Disponível em: <http://bvsms.saude. gov.br/bvs/saudelegis/sas/2008/prt0647_11_11_2008. html>. Acesso em: 13 maio 2015.

Portaria $\mathrm{n}^{\circ} 1.082$, de 23 de maio de 2014.

Redefine as diretrizes da Política Nacional de Atenção Integral à Saúde de Adolescentes em Conflito com a Lei, em Regime de Internação e Internação Provisória (PNAISARI), incluindo-se o cumprimento de medida socioeducativa em meio aberto e fechado; e estabelece novos critérios e fluxos para adesão e operacionalização da atenção integral à saúde de adolescentes em situação de privação de liberdade, em unidades de internação, de internação provisória e de semiliberdade. Diário Oficial [da] União. Brasília, DF, 24 maio 2014. Disponível em: <http://bvsms.saude.gov.br/bvs/saudelegis/gm/2014/prt1082_23_05_2014.html>. Acesso em: 13 maio 2015.

Presidência da República. Casa Civil. Subchefia para Assuntos Jurídicos. Lei no 8.069, de 13 de julho de 1990. Dispõe sobre o Estatuto da Criança e do Adolescente e dá outras providências. Diário Oficial [da] União, Brasília, DF, 16 jul. 1990. Disponível em: <http://www.planalto.gov.br/ccivil_03/LEIS/L8069. htm>. Acesso em: 13 maio 2015.

Resolução ${ }^{\circ}$ 119, de 11 de dezembro de 2006. Conselho Nacional de Direitos da Criança e do Adolescente. Dispõe sobre o Sistema Nacional de Atendimento Socioeducativo e dá outras providências. Diário Oficial [da] União. Brasília, DF, 11 dez. 2006. 
Disponível em: <http://dh.sdh.gov.br/download/resolucoes-conanda/res-119.pdf>. Acesso em: 13 maio 2015.

Resolução $\mathrm{n}^{\circ}$ 160, de 18 de dezembro de 2013, do Conselho Nacional de Direitos da Criança e do Adolescente. Aprova o Plano Nacional de Atendimento Socioeducativo. Diário Oficial [da] União. Brasília, DF, 19 dez. 2013. Disponível em: <http://dh.sdh.gov.br/download/resolucoes-conanda/res-160.pdf $>$. Acesso em: 13 maio 2015.

Secretaria Especial de Direitos Humanos da Presidência da República - SEDH/PR. Lei n ${ }^{\circ}$ 12.594, de 18 de janeiro de 2012. Institui o Sistema Nacional de Atendimento Socioeducativo (Sinase), regulamenta a execução das medidas socioeducativas destinadas a adolescente que pratique ato infracional; e altera as Leis nos 8.069, de 13 de julho de 1990 (Estatuto da Criança e do Adolescente); 7.560, de 19 de dezembro de 1986, 7.998, de 11 de janeiro de 1990; 5.537, de 21 de novembro de 1968; 8.315, de 23 de dezembro de 1991; 8.706, de 14 de setembro de 1993, os Decretos-Leis nos 4.048, de 22 de janeiro de 1942; 8.621, de 10 de janeiro de 1946, e a Consolidação das Leis do Trabalho (CLT), aprovada pelo Decreto-Lei n 5.452 , de $1^{\circ}$ de maio de 1943. Diário Oficial [da] União. Brasília, DF, 19 jan. 2012b. Disponível em: <http://www.planalto.gov.br/ ccivil_03/_ato2011-2014/2012/lei/112594.htm>. Acesso em: 13 maio 2015.

Secretaria Especial de Direitos Humanos da Presidência da República - SEDH/PR. Programas: de Garantia de Direitos da Criança e do Adolescente. 2012c. Disponível em: <http://www.sdh.gov.br/assuntos/criancas-e-adolescentes/programas/fortalecimento-de-conselhos/garantia-de-direitos-da-crianca-e-do-adolescente>. Acesso em: 13 maio 2015.

Secretaria Especial de Direitos Humanos da Presidência da República - SEDH/PR. Conselho Nacional de Direitos da Criança e do Adolescente - CONANDA. Construindo a Política Nacional dos Direitos Humanos de Crianças e Adolescentes e o Plano Decenal dos Direitos Humanos de Crianças e Adolescentes - 2011-2020. Documento Preliminar para Consulta Pública. 2010b. Disponível em: <http://portal. mj.gov.br/sedh/conanda/Politica\%20e\%20Plano\%20
Decenal\%20consulta\%20publica\%2013\%20de\%20outubro.pdf>. Acesso em: 13 maio 2015.

FERNANDES, F. M. B.; MOREIRA, M. R.; REZENDE, M. O direito à saúde de adolescentes cumprindo medidas socioeducativas de privação de liberdade. Revista Saúde \&t Direitos Humanos, Rio de Janeiro, Ano 5, $\mathrm{n}^{\circ}$ 5, 2008, p. 111-126. Disponível em: <http://www.ensp. fiocruz.br/portal-ensp//gdihs/arquivos/5C7BBCAA8F A1B03CABE3EEA25AD0663.pdf $>$. Acesso em: 13 maio 2015

HORTA, N.; SENA, R. Abordagem ao Adolescente e ao Jovem nas Políticas Públicas de Saúde no Brasil: Um Estudo de Revisão. Physis: Revista de Saúde Coletiva, Rio de Janeiro, v. 20, n. 2, 2010, p. 475-495. Disponível em: <http://www.scielo.br/pdf/physis/v20n2/ a08v20n2.pdf $>$. Acesso em: 13 maio 2015.

LOPEZ, S.; MOREIRA, M. Quando uma proposição não se converte política? O caso da Política Nacional de Atenção Integral à Saúde de Adolescentes e Jovens PNAISAJ. Ciên. Saúde Colet., Rio de Janeiro, v. 18, n. 4, p. 1179-1186, 2013. Disponível em: <http://www.scielo. $\mathrm{br} / \mathrm{pdf} / \mathrm{csc} / \mathrm{vl}$ nn4/31.pdf $>$. Acesso em: 13 maio 2015.

OLIVEIRA, M.; ASSIS, S. Os adolescentes infratores do Rio de Janeiro e as instituições que os "ressocializam”. A perpetuação do descaso. Cad. Saúde Pública, Rio de Janeiro, v. 15, n. 4, p. 831-844, out./dez., 1999. Disponível em: <http://www.scielosp.org/pdf/csp/ v15n4/1023.pdf >. Acesso em: 13 maio 2015.

\section{ORGANIZAÇÃO DAS NAÇÕES UNIDAS PARA A} INFÂNCIA (UNICEF). Relatório situação mundial da infância 2012: crianças em um mundo urbano. 2012. Disponível em: <www.unicef.org/sowc2012>. Acesso em: 13 maio 2015.

RAPOSO, C. A Política de Atenção Integral à Saúde do Adolescente e Jovem: uma perspectiva de garantia de direito à saúde? Em Pauta, Rio de Janeiro, v. 6, n. 23, p. 117-138, 2009. Disponível em: < http://www.e-publicacoes.uerj.br/index.php/revistaempauta/article/ view/450/548>. Acesso em: 13 maio 2015. 
SILVA, E. R. A.; GUERESE, S. Adolescentes em conflito com a lei: situação do atendimento institucional no Brasil. Instituto de Pesquisas Econômicas Aplicadas - IPEA. Texto para Discussão, Brasília, DF, n. 979, 2003. Disponível em: $<$ http://repositorio.ipea.gov.br/bitstream/11058/2933/1/TD_979.pdf>. Acesso em: 13 maio 2015.

VILAS BOAS, C. C.; CUNHA, C. F.; CARVALHO, R.

Por uma política efetiva de atenção integral à saúde do adolescente em conflito com a lei privado de liberdade. Revista Médica - UFMG, Belo Horizonte, v. 20, n. 2, 2010. Disponível em: <http://www.rmmg.org/artigo/ detalhes/317>. Acesso em: 13 maio 2015.

Recebido para publicação em março de 2015

Versão final em agosto de 2015

Confllito de interesses: inexistente

Suporte financeiro: não houve 